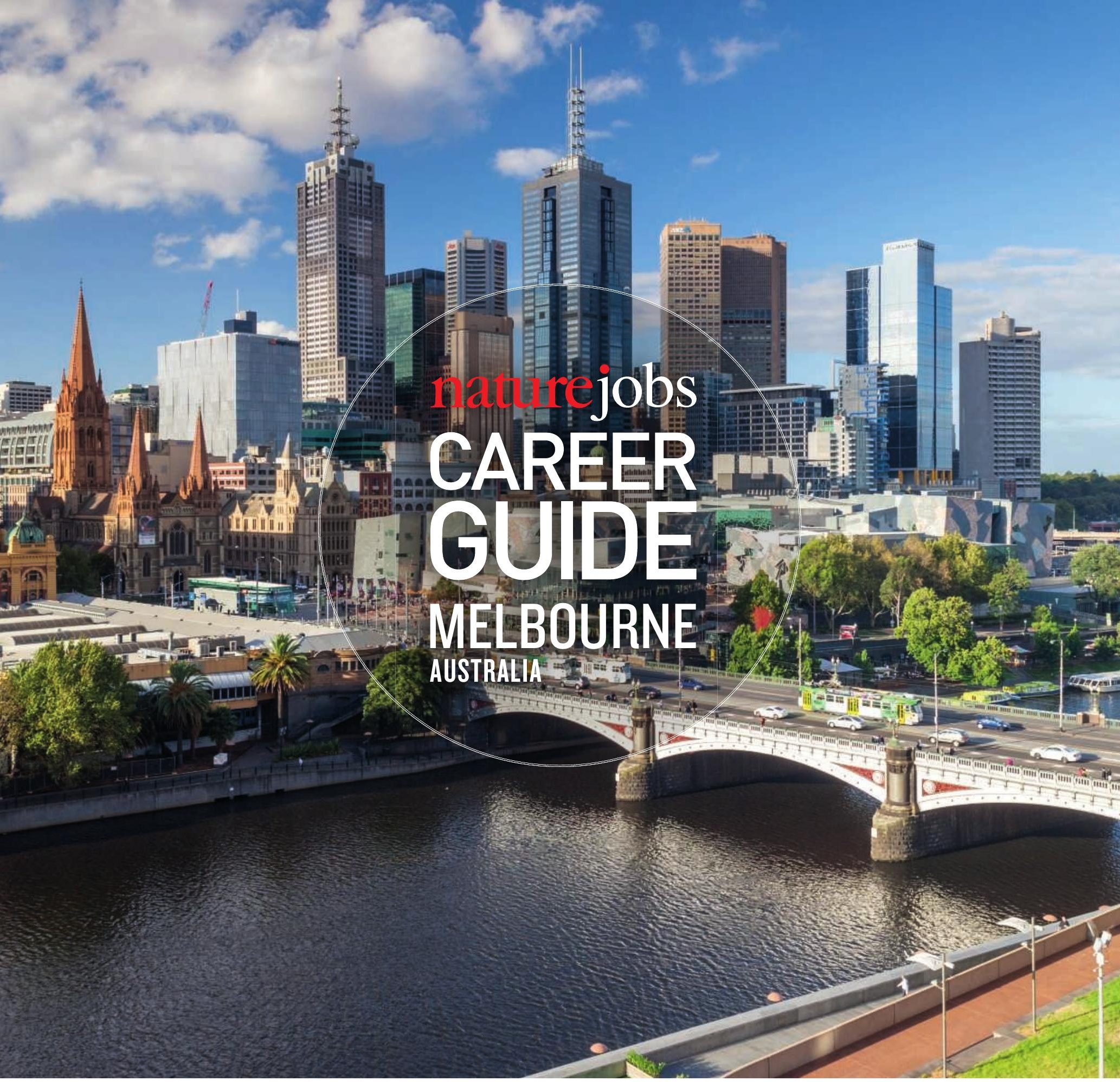

WELCOMETO

MELBOURNE,

WHERESCLENCE IS

FUELLED BY A BETTER

CLASSOF COFFEE.
BY JAMES MITCHELL CROW

$\mathrm{W}$ hen Irish-born materials scientist Cathal O'Connell finished his undergraduate degree at Trinity College, Dublin, in 2008, he started looking for opportunities to apply his knowledge to biological challenges. "Australia was the obvious place to come," he says.

It was a pragmatic move. With a total population of approximately 24.5 million, Australia is home to around only $0.3 \%$ of the world's population - but it produces $2.6 \%$ of the high-quality research, with a particular focus on biomedicine. And Australia's weightiest contributor to biomedical research is Melbourne. Two of the country's top three universities for life science, Monash University and the University of Melbourne, are based here (see 'Ahead of the pack').

"In biomedical research, only two cities in the world, Boston and London, would compare to Melbourne," says Ian Smith, vice-provost for research and research infrastructure at Monash, who moved from the United Kingdom to Australia in 1984.

Besides its two biggest universities, Melbourne boasts six others with their own noted research strengths, along with renowned medical research institutes and several 
> large research hospitals. These institutes employing more than 10,000 scientists, clinicians and technical staff — are generally clustered into geographic hubs, fostering easy collaboration (see 'Clustering innovation').

The state of Victoria consistently wins around $45 \%$ of Australia's National Health and Medical Research Council funding. "That tells you something about the quality of research here," says Smith. Core strengths include cancer, infection and immunity, rational drug design, and medical devices, he says, offering good career opportunities for young researchers.

Historically, Melbourne has lagged behind at cashing in on those strengths. "We don't have a lot of the industries that should be coming out of universities like Monash, so career opportunities outside academia are a little limited," Smith says. "But the culture is changing."

Medical devices is one area in which Melbourne researchers can find significant commercial role models - most famously Cochlear Limited, which commercialized the 'bionic ear', a hearing implant developed by Graeme Clark at the University of Melbourne. This device, which connects electrodes to auditory neurons, was a highly collaborative effort. "You had physicists and engineers, biologists and materials scientists, all working together to solve a problem," says O'Connell.

Today, O'Connell manages a collaboration of his own: BioFab3D, a recent addition to Melbourne's biomedical research scene. Launched in late 2016 , BioFab3D is pioneering the $3 \mathrm{D}$ printing of living cells to replace damaged or diseased tissues. Supported by the University of Melbourne, O'Connell's lab is located at St Vincent's Hospital, and is also co-funded by the University of Wollongong in New South Wales, the Royal Melbourne Institute of Technology University and Swinburne University of Technology.

"This lab is a small pathfinder for what will come later," says O'Connell, pointing to plans for a new Aus $\$ 180$ million (US\$135 million) facility devoted to biomedical engineering called the Aikenhead Centre for Medical Discovery.

The centre will focus on exactly the kind of collaboration that O'Connell was hoping to find when he moved to Melbourne: biomedicine meeting materials science. He

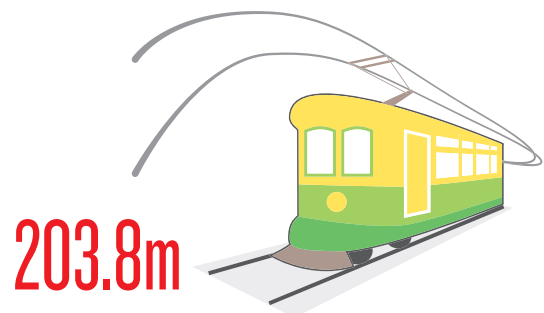

Melbourne has the world's largest urban tram network. It took passengers on 203.8 million trips in 2015.

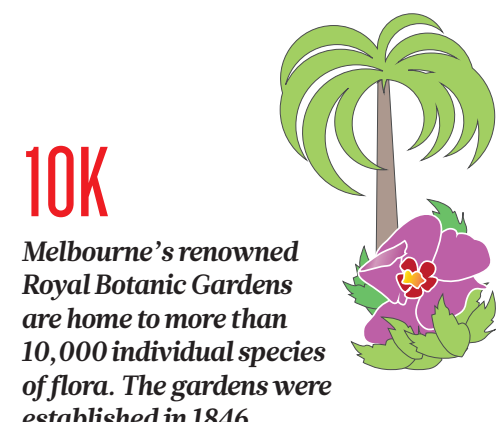
established in 1846

\section{CLUSTERING INNOVATION}

Melbourne's research landscape is characterized by small clusters of collaborating institutes around leading universities. The University of Melbourne in Parkville, for example, enjoys the close company of the Royal Melbourne Hospital, the Peter MacCallum Cancer Centre and many more medical research institutes. They are all a half-hour walk from another world-leading university: the Royal Melbourne Institute of Technology University.

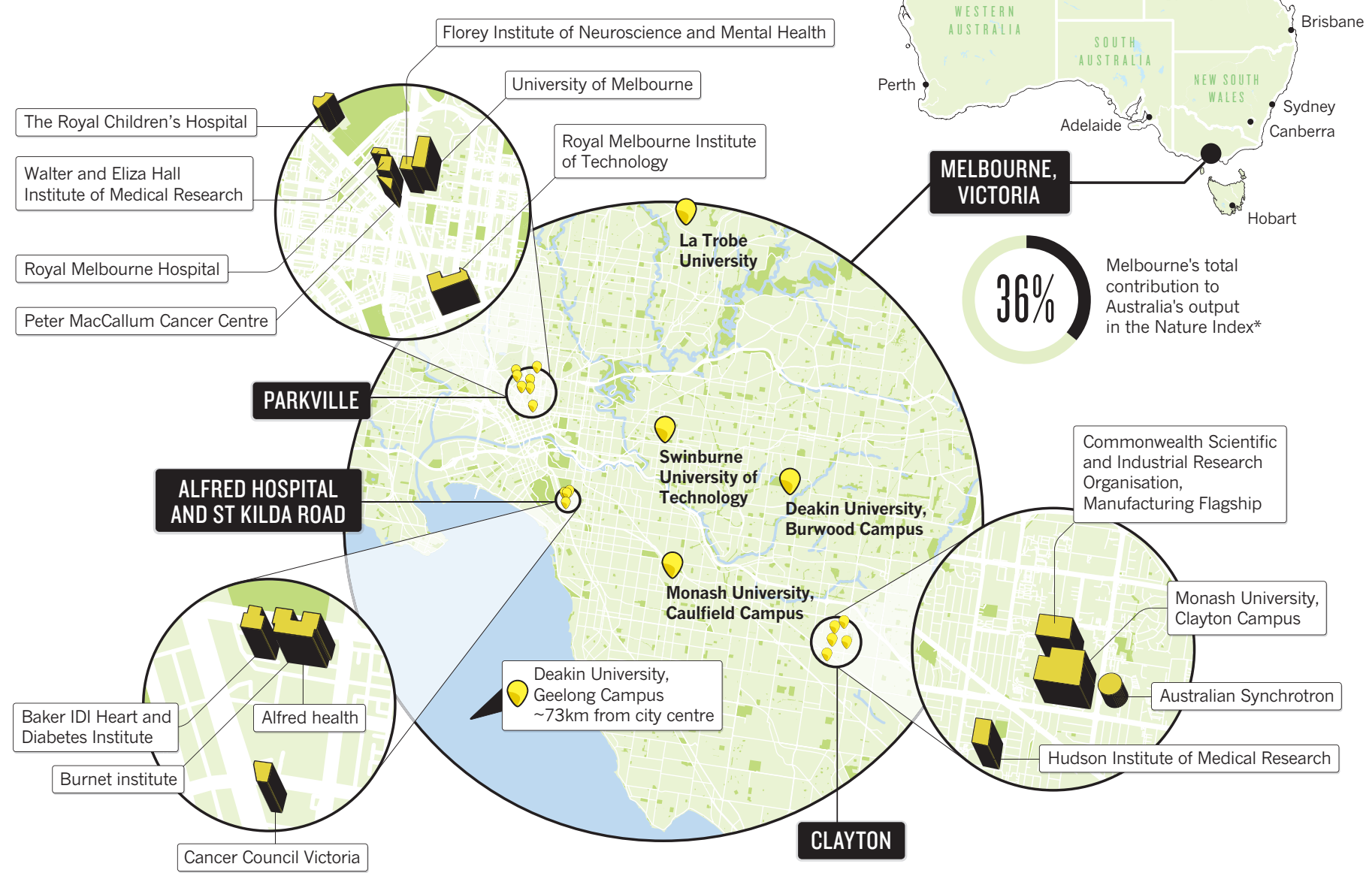




\section{A CAREER IN COFFEE}

Monika Fekete is sitting in the Melbourne sunshine sipping a locally roasted, cold-drip coffee. All in the name of research.

Just over 18 months ago, the Budapest-born scientist was coming to the end of a postdoc in chemical engineering at Monash
University during which the city's renowned café culture had her hooked. "Coffee is a Melbourne thing - you meet lots of people very passionate about it," she says. Today, Fekete runs a consultancy helping to bring scientific rigour to Melbourne's buzzing coffee making and brewing scene.

She's run double-blind tastings to test new products, and helped local specialist roasters use refractometry to consistently achieve the perfect quantity of dissolved solids in an espresso. "In Budapest, coffee was something you drank with a couple of sugars tipped in to get you through exam revision," she says. In Melbourne, going out for coffee is an event in itself.

Melbourne's wider gastronomical and social scene is exceptional. "We've never had a bad meal," says Tina Overton, who joined Monash from the University of Hull, UK, in 2014.

"Melbourne is an easy place to enjoy yourself," she adds. "We like to go into the city, down by the Yarra River, where you can sit and admire the view. There are so many lovely places. It's a very safe, laid-back city, but there's always something going on." J.M.C.

\section{AHEAD OF THE PACK}

In funding and academic output, the University of Melbourne and Monash University lead the city's research efforts.

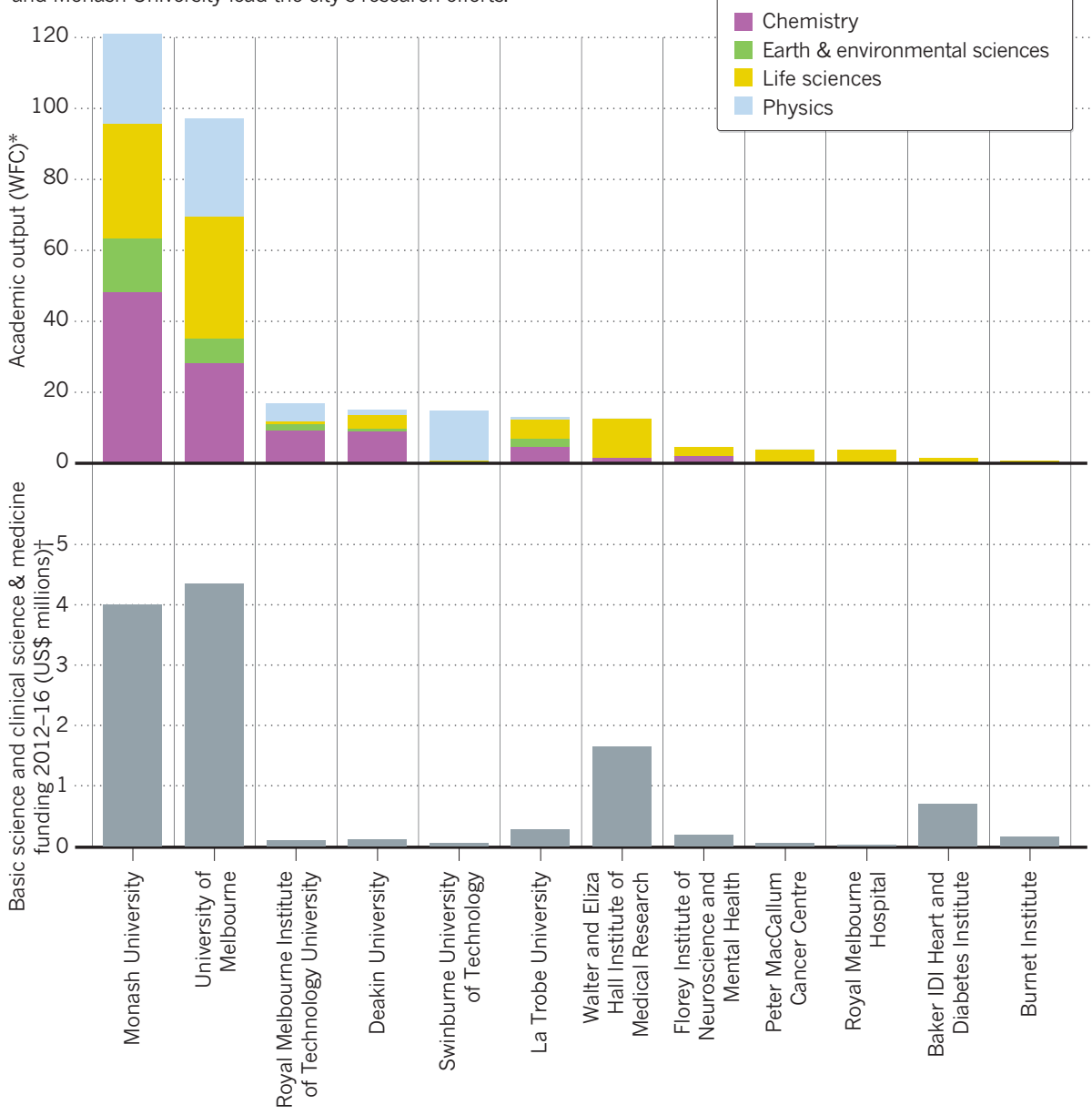

* Weighted fractional count (WFC) accounts for the relative contribution of authors to papers in high impact journals and applies a weighting to balance subject coverage. Data from 2016 calendar year. Source: Nature Index.

† Funding from competitive grants obtained by researchers listed as working at Melbourne institutions from 2012-2016. Non-competitive finances, such as the funding behind the Australian Synchrotron, are excluded. Source: Dimensions/ÜberResearch.

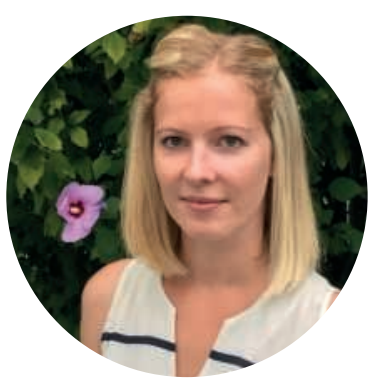

VICTORIA BLAIR

Organometallic chemist Victoria Blair moved from Strathclyde University in her native Scotland to work as a postdoc at Monash University in May 2011. She started her own research group in 2014 and gained Australian citizenship the following January.

\section{How did you find the move to Australia?}

We touched down in May - in the Australian winter, which has the same temperatures as a Scottish summer. After I got on Australian time, I started my postdoc. Since then l've applied for my own funding and set up a research group through the Australian Research Council. I came here thinking l'd be here for a year or two, but I fell in love with the city.

What do you love about it?

It's vibrant. Melburnians are so outdoors-oriented; they've got nature trails and cycling trails all over the city. Melbourne has been voted by The Economist Intelligence Unit's Global Liveability Ranking as the most liveable city in the world for six years running. Australians are friendly and speaking the same language was helpful. It didn't take long to make friends. The food is some of the best I've had. When I moved here six years ago, I told myself that, although it was the other side of the world, I could be back home in 24 hours if it doesn't work out.

What's the scientific environment like?

There's a lot of collaboration. We have joint conferences regularly with other universities, and there are many partnerships between medical and non-medical researchers and institutes in Melbourne. There are also grants across Australia that encourage links between professional teams. That helps to progress the field really quickly. The

culture is geared towards that. 
- cites an example from 2015, when Spanish surgeons needed a replacement ribcage for a patient with a tumour growing in his chest wall. The scientists asked Melbourne firm Anatomics to design it, uploading their patient's computed tomography scans directly to the company. The ribcage was printed in Clayton, at the centre for the Commonwealth Scientific and Industrial Research Organisation, the national research agency.

Science isn't the only thing to recommend Melbourne. The city has topped The Economist's index of the world's most liveable cities for the past six years (see 'A career in coffee').

If you look up almost anywhere in Australia, you'll be greeted by a clear, radio-quiet night sky, says Alan Duffy, an astronomer at Swinburne who moved to Australia in 2009 from the Jodrell Bank Centre for Astrophysics in Manchester, UK. "Australia always seemed like this incredible exotic land," Duffy says. "Scientifically, at least in astronomy, it is one of the top countries."

Last year, Swinburne won Australian Research Council funding to establish a new Centre of Excellence for Gravitational Wave Discovery. And, with state government support, Swinburne and Melbourne universities have installed the Southern Hemisphere's first dark-matter detector - housed in Victoria in a gold mine, a kilometre underground, to protect it from interference from atmospheric particles.

Swinburne's strength in the emerging field of data science will be crucial for the project. The astronomers need computer scientists to develop ways to handle astronomically sized data sets. "It's given rise to a really exciting new discipline - the skills used to explain exploding stars can be used to understand issues such as traffic management," Duffy says.

"Melbourne prides itself on creation and creativity, and you can see that - from the artistry we put into preparing coffee, to the way people dress, to the fact that public talks on the most esoteric scientific matters are sell-outs."

"Melbourne is a melting pot of ideas and a very innovative place to live and work in," O'Connell agrees. "It's a great place to live in general - there's a great art scene, a music scene, a beautiful seafront."

"I've known many astronomers who would rather leave astronomy than leave Melbourne," Duffy says. "I always look forward to coming back here." -

James Mitchell Crow is a science writer based in Melbourne.

\section{THE FINE PRINT}

\section{What you need to know}

Australia's Temporary Work (Skilled) visa system is currently in flux after the Australian government announced an overhaul in April. Most researchers coming to Australia have used this visa, which allows skilled workers with dependents to work in their chosen field for up to four years. Applicants may be sponsored by an employer or considered a good fit for an open position.

The Temporary Work (Skilled) visa costs start at Aus $\$ 2,120$ (US\$1,636) and applications were usually processed within 90 days. After two years on this visa, sponsored workers and their dependents could be nominated for a permanent residency visa by their employer. These rules are being changed gradually, with a full overhaul due in March 2018.

Another option is the Skilled Independent visa (subclass 189). This is aimed at English-speaking applicants under the age of 50 who are qualified to fill positions relevant to the country's skill shortage list, but who are not sponsored by an employer. The price starts at Aus $\$ 3,600$ and the visa is assessed under a pointsbased system. Successful applicants can stay in Australia permanently.

Use the Australian government's Visa Finder page (www.border.gov.au/ Trav/Visa-1) to stay up to date.

\section{OPPORTUNITIES \& CONTACTS}

International Postgraduate Research Scholarships provide tuition fees and health cover for two years for master's degrees and three years for doctoral degrees. Melbourne's bigger universities also offer their own postgraduate scholarships.

Commonwealth Scientific and Industrial Research Organisation postdoctoral fellowships are available for $\mathrm{PhD}$ graduates with no more than three years of postdoc experience.

The National Health and Medical Research Council offers five-year fellowships for health and medical researchers.

The Australian Research Council offers three-year Discovery Early Career Researcher Awards to scientists within five years of being awarded a PhD. J.M.C.

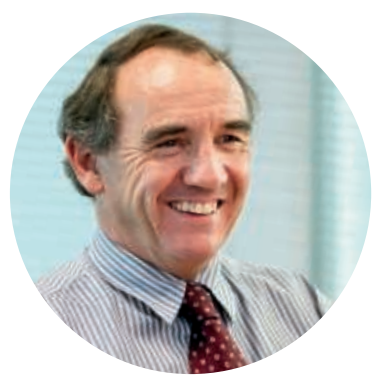

\section{JIM McCLUSKEY}

Cosmopolitan Melbourne has changed dramatically since Jim McCluskey's last stint in the city - he worked as a researcher at Monash University between 1987 and 1990. McCluskey returned in 1997 as chair of microbiology and immunology at the University of Melbourne, and became deputy vice-chancellor (research) in 2011. A native of Perth, where he studied medicine, he has also worked in Adelaide and Washington DC.

\section{What is it like working at the} University of Melbourne?

We're surrounded by five major public hospitals, four independent research institutes and a large number of nongovernmental organizations and agencies. The Royal Melbourne Institute of Technology University is a few hundred yards away. Ten thousand biomedical researchers work here.

You go for coffee, bump into people and have great conversations. We have around

20,000 international students (we have approximately 50,000 overall), and there are roughly 120 languages spoken on campus.

What attracts researchers to Melbourne?

There are great collaborations across disciplines. We also have the 'two-body opportunity' when someone's partner also needs a job, and having this diverse workforce means you can map jobs to skills much better. There are great schools and a growing public transport system. If there's a downside, it's expensive property prices.

\section{What's the city like?}

It is globally connected, cosmopolitan and dynamic, with great neighbourhoods, restaurants, theatres and music. The Yarra Valley wineries are nearby. My family and I spend a lot of time enjoying Port Phillip Bay. We have a weekend property just over an hour away. We're surrounded by birds and kangaroos there. When I get fed up reading academic board papers, I climb on the mower and cut the grass. It's a very Zen activity. At night the sky is inky and dotted with stars. It's wonderful. 